\title{
Religious affiliation, combat exposure, and PTSD among military combatants in north east Nigeria
}

\begin{abstract}
This study examined the influence of combat exposure on PTSD among military combatants in the North Eastern part of Nigeria. A total of 249 respondents participated in the study through a purposive sampling technique. Participants include both officers and men of the Nigerian army on the operation LAFIA DOLE. An ex-post facto design was employed in the study. It was hypothesized that religious affiliation and combat exposure would have a significant interaction effect on PTSD which was not significant $(3,249) 295.187=\mathrm{P}>0.05)$. Religious affiliation was found to be significant on PTSD $(1,249)=1485.215 \mathrm{P}<0.05)$, and combat exposure found to be significant on PTSD $(3,249) 3092.335=130.206, \mathrm{P}<0.05$. Furthermore, it was hypothesized that religious affiliation would have a significant main effect on Avoidance symptoms and re-experiencing symptoms; and both turned out to be significant, with $\mathrm{F}(1,249)$ $228.546=\mathrm{P}<0.05)$ for avoidance and $(1,249) 168.379=\mathrm{P}<0.05$ for re-experiencing symptoms respectively. Religious affiliation was found not to be significant on hyperarousal symptoms $(1,249) 109.091=\mathrm{P}>0.05$. There is a need for combatants' religious coping options to be buffered, this would help in stress buffer and other selfmanagement techniques inherent in their cultural values.
\end{abstract}

Volume 9 Issue 2 - 2018

\author{
Binan Evans Dami,' Abel James, ${ }^{2}$ Dagona \\ Zubairu, ${ }^{3}$ Haruna Karick, ${ }^{3}$ Arin James Izang' \\ 'Medecins du Monde, Nigeria \\ ${ }^{2}$ Nigerian Military Kinnasara Baracks Monguno, Maiduguri \\ ${ }^{3}$ Department of General and Applied Psychology, University of \\ Jos, Nigeria
}

Correspondence: Binan Evans Dami, Medecins du Monde, Nigeria, Email evansbinan@gmail.com

Received: January 16,2018 | Published: March 27, 2018

\section{Religious affiliation, combat exposure and PTSD among military combatants in north east Nigeria}

From an advent of wars and armed conflict in our society today, it has become quite important to note that the role of the military in a country as Nigeria has become conspicuous as the military has been outstretched in many instances. The military personnel has been taken off their homes to new areas of duty in order to curb insurgency in the Northern part of Nigeria, crimes in the Eastern and Western part of the country and even agitations in other parts of the country. At the continental level, our military has been exposed to high powered military missions in Sudan, Liberia, Sierra Leone, and a host of other countries. However, despite these various exposures to combat and many more, some of thimilitary personnel come back with praises of a successful outcome, while others come back with many pains. The role of religion cannot be underemphasized in the lives of these combatants as most of them belong to a particular religious sect and they heed to their various religious practices which in turn may likely be a buffer for them even while on the battlefield. Findings from the Baltimore Epidemiologic Catchment Area Study indicated that individuals who reported ever seeking spiritual comfort at Wave 3 assessment had decreased odds of suicidal ideation at Wave 4 as compared to those who reported never seeking spiritual comfort at Wave $3 .{ }^{1}$ Literature examining the relationship between spirituality, religion, and anxiety disorders and suicide is less robust. ${ }^{1}$ Subjective religiosity (the extent religious beliefs are a source of comfort/strength) was shown to be associated with both women veterans ${ }^{2}$ and male veterans ${ }^{3}$ with sexual assault experience. Spiritual well-being was also found to be a mediator of the effect of a mantra (a sacred word or phrase repeated over and over) intervention to decrease PTSD symptoms in veterans with military trauma. ${ }^{4}$ Other studies have examined interventions that include a spirituality component to help promote resilience, reduce health risks, ${ }^{6}$ integrate health promotion and wellness, ${ }^{7}$ and reduce PTSD symptoms in veterans exposed to trauma, ${ }^{8}$ though all indicate that further, more robust research is warranted in these areas. In a great attempt, researchers have been able to explore resilience, stress recovery factors available to the military which will help them as a buffer factors with the traumatic stress often inherent in combat-exposure: the role of positive and negative religious coping, and additionally, the meanings they attach to their duties. One type of constructive response to trauma and stress found to have positive effects on mental health involves the construct of religious copin..$^{9-11}$ Nigeria has a multicultural society and individuals from this society are incorporated into the army keeping in mind their various religious sect. In Nigeria, Christianity, Islam, and African traditional religion are the dominant religious sects and these religious beliefs inherent in these sects are likely to stand in as in as buffers. Studies have seen the positive relationship between religion and health outcomes. ${ }^{12}$ Fontana \& Rosenheck ${ }^{13}$ found that traumatic combat experience, mediated by guilt, weakened the religious faith of veteran. Chen \& Koenig ${ }^{14}$ studies on traumatic stress and religion provided the basis for other studies to hinge on. Mental health treatment has traditionally eschewed addressing religious matters, regardless of the diagnoses, despite evidence suggesting that religious issues are intimately tied to psychological well-being ${ }^{14,15}$. Research studies have shown that Veterans report guilt and shame related to their traumatic military experiences. ${ }^{13,16}$ These emotional responses are understandable given the extremely challenging circumstances of war, such as being required to kill other human beings. ${ }^{17}$ As well, guilt and shame are often related to actions taken or witnessed during the war that are directly opposed to personal values and/or personal spiritual and religious assumptions. Indeed, many survivors seem to be morally "wounded" by their traumatic military experience. Litz et al. ${ }^{16}$ suggest that experiences in war, such as witnessing and perpetrating violence, facing ethical situations without knowing how to respond, and lacking the ability to help those in need can contradict deeply held moral beliefs that may be directly tied to personal religiosity. The Veteran trauma survivor 
may struggle to make meaning out of the experiences, by either trying to reconcile the trauma with their current beliefs or by changing their beliefs as a result. In addition, guilt and shame may trigger distressing intrusive recollections of the moral transgression and consequently lead to avoidance of trauma reminders and general withdrawal from others. ${ }^{16}$ These traumatic experiences may shatter the Veterans faith in a "just" God, alter spiritual and religious systems or even challenge meaning and purpose in life. ${ }^{18}$

Falsetti et al. ${ }^{19}$ found that after experiencing their first trauma, individuals who developed PTSD were more likely to report changes in religious beliefs than those who did not develop PTSD. Drescher \& Foy $^{20}$ reported that $74 \%$ of Vietnam Veterans enrolled in PTSD residential treatment had difficulty reconciling their religious beliefs with the traumatic events they had experienced in Vietnam. Finally, Fontana \& Rosenheck ${ }^{13}$ found that traumatic combat experiences, mediated by guilt, weakened the religious faith of Veterans. These studies support the notion that trauma and PTSD can impact one's experience of religiosity. However, there is limited research on the way existing personal religiosity predicts traumatic stress, specifically as it relates to PTSD. Chen \& Koenig ${ }^{14}$ review of the traumatic stress and religion literature yielded some good results on religion and health outcomes. Trauma is a universal phenomenon, experienced all over the world over and across time. Poets and novelists as far back as Homer and Shakespeare were among the first to record the profound impact of trauma and its subsequent stressors on human cognition, behavior, and emotion. ${ }^{21}$ Exposure to traumatic events, such as war, conflict, natural and human-made disasters, assault and life-threatening illnesses are common, with over two-thirds of the general population likely to be exposed to a traumatic incident in their lifetime..$^{22}$ Brewin et al. ${ }^{23}$ also studied predictors of PTSD and showed that pre-trauma risk factors have relatively weak predictive effects, while trauma intensity and post-trauma risk factors have somewhat stronger predictive effects. For instance, a lack of social support, life stress, trauma severity, childhood abuse, and other adverse childhood experiences were strong predictors of PTSD.

Exposure to traumatic life events can consequently have a series of serious adverse psychological effects. In the last three decades, there has been an increase in the discussion of trauma and its effects, with a particular focus on Post Traumatic Stress Disorder (PTSD). ${ }^{24}$ Previous systematic reviews have documented PTSD to be the most commonly studied psychopathology in the aftermath of trauma. ${ }^{25}$ PTSD is characterized by several interrelated symptom clusters including reexperiencing symptoms (e.g., intrusive thoughts, recurrent dreams, flashbacks, distress and physiologic reactivity upon exposure to trauma cues), avoidance and emotional numbing symptoms (e.g., avoidance of traumatic reminders, anhedonia, detachment from others, restricted emotional experiences, sense of foreshortened future), and hyperarousal symptoms (e.g., sleep difficulties, irritability and anger, concentration problems, hypervigilance, exaggerated startle). ${ }^{26}$ PTSD is often been studied among military personnel in relation to combat trauma. ${ }^{27,28}$ The effect of combat on PTSD in military personnel is a major concern among the public, military leaders, and policy makers in the areas of policy re-draft, ${ }^{29}$ indeed, it can be a debilitating consequence of severe or life-threatening trauma ${ }^{25}$ Moreover, PTSD can cause substantial distress and interfere with personal and social functioning, subsequently leading to social withdrawal, anger, and aggression. $^{30,31}$ Furthermore, PTSD in military populations has a pervasive impact on military readiness and the accomplishment of military goals. ${ }^{32}$

Meis et al. ${ }^{33}$ post-traumatic stress disorder related emotional numbing in veterans promotes emotional withdrawal from intimate relationships and without decreased positive engagement, intimacy, and opportunities for effective and validating communication. Additionally, angry outbursts can reduce the frequency and effectiveness of communication, problem-solving and social support. ${ }^{34}$ For the purpose of this study, Religious affiliation refers to one's religious belongingness, either Christianity, Islam, or African traditional Religion as would be measured in the study.

\section{Statement of problem}

The conflict has become a state of being in many African countries including Nigeria. These conflicts have led to frequent deployment and re-deployment of military personnel across countries through the African Union and the ECOWAS Monitoring Group. Continentally, our military is engaged in bringing peace and sanity to countries where there is the absence of peace. Internally, our military is involved in peacekeeping missions such as operations LAFIYA DOLE, ZAMAN LAFIYA, BOYONA, CROCODILE TEARS, and much more as each operation comes with its modified name. This personnel is exposed to series of warfare and little or no much attention is being provided to them in the relevant areas of need to meet up with the challenges they seem to be having. In most instances, some of them are away from home for months, others years, while others are gone not to be seen again. This scenario is likely to create constant anxiety among family members with respect to when they are likely to see their parent. Furthermore, the personnel on deployment is likely to be in separation anxiety or death anxiety whenever the thoughts of his family members flash through his mind. More so, since Nigeria is a multicultural society, the role of religion and culture cannot be underemphasized as most of this personnel belong to a particular religious sect. These sects have their inherent religious beliefs embedded in their religious stance and these beliefs are likely to count in the feelings of psychological distress and in some instances likely to serve as stress buffer options. However, despite these existing religious beliefs, some of this military personnel are likely to be reported by family members after return from missions to exhibit some strange kind of behaviors. When military personnel return from military observation and military operations, they are often noticed by significant others to start exhibiting some maladjusted symptoms especially in interactions and even events that expose them to the public. Studies have been conducted on military combat exposure and PTSD especially in Kosovo, the Middle East and some other regions $\mathrm{s}^{35,36}$ and a few in Nigeria. ${ }^{37}$ Religion is a very significant aspect of the military personnel that has not been much incorporated into studies and this study will try to explore religious affiliation whether being a Christian, Muslim, or practicing African Traditional Religion has any significant impact on PTSD symptoms among the said military personnel; also, to examine the influence of combat exposure on PTSD symptoms among military personnel on operation LAFIA DOLE in North East Nigeria.

\section{Aim of study}

The aim of this study is to assess the impact of religious affiliation and combat exposure on PTSD among military combatants. 


\section{Hypotheses}

1. There will be a significant interaction effect of religious affiliation and combat exposure on PTSD among military personnel.

2. There will be a significant main effect of religious affiliation on PTSD among military personnel.

3. There will be a significant main effect of combat exposure on PTSD among military personnel.

4. There will be a significant main effect of religious affiliation on avoidance symptoms

5. There will be a significant main effect of religious affiliation on re-experiencing symptoms.

6. There will be a significant main effect of religious affiliation on hyperarousal symptoms.

\section{Method}

\section{Measure}

The Combat Exposure Scale (CES) developed by Keane et al. ${ }^{38}$ is a 7-item self-report measure that assesses wartime stressors experienced by combatants. Items are rated on a 5-point frequency (1 $=$ "no" or "never" to $5=$ "more than 50 times"), 5 -point duration (1 $=$ "never" to $5=$ "more than 6 months"), 4-point frequency $(1=$ "no" to $4=$ "more than 12 times") or 4-point degree of loss ( 1 = "no one" to $4=$ "more than $50 \%$ ") scale. Respondents are asked to respond based on their exposure to various combat situations, such as firing rounds at the enemy and being on dangerous duty. The total CES score (ranging from 0 - 41) is calculated by using a sum of weighted scores, which can be classified into one of five categories of combat exposure ranging from "light" to "heavy." The CES was developed to be easily administered and scored and is useful in both research and clinical settings (U.S. Department of Veterans Affairs, 2016). Internal consistency: The mean score on the Combat Exposure Scale was $25.57(S D=10.12)$; scores ranged from 1 to 41 . Coefficient alpha was calculated and yielded a value of .85 . This high degree of reliability indicates that the items are measuring the same or a very similar construct. As a second measure of internal consistency, we computed item-remainder total score correlations. The average correlation was .75 (range $=.64$ to .83$)$.

Principal-components analysis. A principal-components analysis using varimax rotation generated a single factor with an eigenvalue greater than 1.0. The item loadings are contained in Table 1 and accounted for $57.6 \%$ of the common variance among the items. Because a single factor accounted for a high percentage of the variance, the scale seems to measure a single, consistent construct of combat exposure. Reliability: Test-retest reliability with a 1-week interval was calculated for all three groups combined, $r(29)=.97, \mathrm{p}$ $<.0001$. There were no between-group differences in the test-retest correlations. The means for Time I and Time 2 were 23.2 and 22.2, respectively, indicating excellent stability over this time period.

Descriptive statistics: The mean scores on the CES were 29.37 $(S D=6.12)$ for the PTSD group and $22.84(S D=10.42)$ for the VVL group, a difference that attained statistical significance, $t(60)=2.98$, $p<.005$. As predicted, the PTSD group reported greater amounts of combat exposure than did the VVL group. This may be attributed to either actual differences in the amount of combat exposure or differences in subjective recall of combat experience by clinically distressed individuals. Scores on the CES were significantly correlated with scores on the Mississippi Scale for the VVL group, $\mathrm{r}(30)=.43$, $p<.01$; however, the corresponding correlation for the PTSD group did not reach statistical significance. The absence of a significant correlation for the PTSD group is likely due to the truncated range of scores for these subjects on the CES and the Mississippi Scale. Neither age nor educational level correlated with scores on the CES. ${ }^{38}$

Also, a PTSD military version questionnaire was administered. The Posttraumatic Stress Disorder Checklist-Military ${ }^{39,40}$ is a self-report rating scale that measures PTSD symptom severity in military veterans. The PCL-M is a 17 -item self-report questionnaire. Items include: "How much have you been bothered by repeated, disturbing, memories, thoughts, or images of a stressful military experience in the past month?," "How much have you been bothered by repeated, disturbing dreams of a stressful military experience in the past month?," and "How much have you been bothered by feeling emotionally numb or being unable to have loving feelings for those close to you?" Participants respond using a 5- point scale that ranges from 1 (not at all) to 5 (extremely). The scale is scored by calculating a total score. This score is derived by adding the responses to all scale items. The total score may range from 17 to 85 , where elevated scores suggest greater severity. Ratings are chosen according to how much the veteran has been disturbed by a particular traumatic military-related incident. The items included on the scale are based on current DSM criteria. In addition, the scale has proven useful with both male and female veteran populations. ${ }^{39}$ This scale has been shown to be both valid and reliable $(\alpha=.96)$ in previous research. The internal reliability of the sample used in the current study was .96 . The PCLM was scored by adding up all the items for a total severity score. A total score of 50 was considered to be PTSD positive in military populations. ${ }^{39}$ Thus, the 44 dependent variable of PTSD was dichotomous ( $1=\mathrm{PTSD}$ vs. $0=$ no PTSD).The percentage of participants that were in the PTSD group was $24.6 \%$ (compared to $68.7 \%$ that was classified as not having PTSD). Because this instrument has not enjoyed popular usage in Nigeria, two weeks test-retest reliability was carried out among 90 soldiers deployed in Mongunu Nigeria and a coefficient of 0.89 was obtained. Religious Affiliation was measured using a discrete scaling category created on the questionnaire. This category asked respondents which religious sect they belong to and they had to identify Christianity (1), or Islam (2), or Others (3).

\section{Research design}

In examining religious affiliation and combat exposure among military combatants in the North Eastern part of Nigeria, an ex-post facto design was employed, and a two way ANOVA was used.

\section{Participants}

This study was carried out among the Nigerian military personnel deployed in the North-eastern part of Nigeria fighting insurgency. The purposive sampling technique was employed to select the participants from 8 task force division; Mongunu and its area of responsibility were purposively chosen. Total sample of two hundred and fifty-one hundred (251) military personnel with combat operational experience in the North-East fighting insurgency that was deployed in their various 
locations were used for the study. Two hundred and fifty-one (251) soldiers participated in the research work, but 250 questionnaires were generated, one was discarded making 249. Participants were within ages 20 to $60,46 \%$ are within the ages of $20-30,33.2 \%$ are within ages of $31-40,20.8 \%$ are within ages $41-50$, and $2.4 \%$ are within ages $50-60 ; 91.2 \%$ males and $6.4 \%$ females, $2.4 \%$ didn't indicate their gender; $97.2 \%$ men and 2.8 officers, $64 \%$ Christians 36\% Muslims, $67.6 \%$ married, $29.2 \%$ single, and $3.2 \%$ divorced; and majority of personnel have exposure to combat.

\section{Procedure}

One of the researchers personally visited the military personnel in their various deployment trenches, meeting points such as calling point and internet browsing, the wounded ones in the Hospital, soldier's club amongst others to administer the questionnaire. Only participants who agreed and were willing to participate in the study were given the questionnaires to fill. The researcher was as flexible as possible during the administration of questionnaire in order to achieve a higher response from participants. The researcher used suitable conversational tunes and reinforces examinees efforts and level of ability. The non-probability (purposive) sampling technique was applied to select the participants from different units in Headquarters 8Task Force Division Nigerian Army, Kinnasara Cantonment Barracks Mongunu, 8 Task Force Division Hospital, 7 Brigade Baga, and 5 Brigade Gubio were used for the study. The questionnaire was self-administered, so it was distributed to the soldiers, One of the researchers being a military psychologist deployed among the soldiers was familiar with the deployment and as well as the population of interest. With the permission of the authority who gathered the soldiers for the study, he was able to interact freely with the personnel. Every participant that met the criteria and accepts participating in the study was allowed. This sampling approach was chosen because the study was made up of the special population that is not commonly found. As a result, only military personnel with combat operational experience were included in the study.

\section{Ethical consideration}

The researcher also obtained permission from the General officer commanding the troops to get informed consent of the participants. Thereafter, the purpose of the study was briefly explained to all the participants with the assurance that information given will be treated with utmost confidentiality. Confidentiality of the deployed military personnel responses and strict adherence to individual privacy were fully assured. Consequently, those willing to participate were made to complete the questionnaires administered to the participants by the clinicians who serve as research confederates in the Division Hospital and its area of responsibility. After 60 minutes, the questionnaires were collected from the participants.

\section{Method of data analysis}

Descriptive statistic was employed to obtain descriptive data and then inferential statistic was used to obtain results with respect to the hypotheses stated earlier.

\section{Result}

(Table 1)

\section{Interpretation}

Table I Test of between-subject effects using a multivariate analysis

\begin{tabular}{|c|c|c|c|c|c|c|}
\hline \multicolumn{7}{|c|}{ Tests of between-subjects effects } \\
\hline \multicolumn{2}{|c|}{ Variables } & \multirow{2}{*}{$\begin{array}{l}\text { Type III Sum of squares. } \\
228.546\end{array}$} & \multirow{2}{*}{$\frac{\text { Df }}{\mathrm{I}}$} & \multirow{2}{*}{$\begin{array}{l}\text { Mean square } \\
228.546\end{array}$} & \multirow{2}{*}{$\begin{array}{l}\mathbf{F} \\
9.624\end{array}$} & \multirow{2}{*}{$\begin{array}{l}\text { Sig. } \\
0.002\end{array}$} \\
\hline \multirow{4}{*}{ Religion } & Avoidance & & & & & \\
\hline & Re- experiencing & 168.379 & I & 168.379 & 6.155 & 0.014 \\
\hline & Hyper arousal & 109.091 & 1 & 109.091 & 1.977 & 0.161 \\
\hline & Post Traumatic Stress Disorder & 1485.215 & I & 1485.215 & 5.655 & 0.018 \\
\hline \multirow{4}{*}{$\begin{array}{l}\text { Combat } \\
\text { Exposure }\end{array}$} & Avoidance & 281.619 & 3 & 93.873 & 3.953 & 0.009 \\
\hline & Re- experiencing & 477.99 & 3 & 159.33 & 5.824 & 0.001 \\
\hline & Hyper arousal & 392.031 & 3 & 130.677 & 2.368 & 0.071 \\
\hline & Post Traumatic Stress Disorder & 3092.335 & 3 & 1030.778 & 3.925 & 0.009 \\
\hline \multirow{4}{*}{ Rel $*$ CE } & Avoidance & 38.779 & 3 & 12.926 & 0.544 & 0.652 \\
\hline & Re- experiencing & 6.637 & 3 & 2.212 & 0.081 & 0.97 \\
\hline & Hyper arousal & 91.261 & 3 & 30.42 & 0.551 & 0.648 \\
\hline & Post Traumatic Stress Disorder & 295.187 & 3 & 98.396 & 0.375 & 0.771 \\
\hline
\end{tabular}

\section{Hypotheses one}

It was hypothesized that there will be a significant interaction effect of religious affiliation and combat exposure on PTSD among military combatants. The result showed no significant interaction effect. The result presented $(3,249) 295.187=\mathrm{P}>0.05$.

\section{Hypotheses two}

It was hypothesized that there will be a significant main effect of religious affiliation on PTSD. Analysis revealed a significant main effect of religion on PTSD. The result presented as $(1,249)=1485.215$ $\mathrm{P}<0.05$. Therefore, the alternate hypothesis is being maintained. 


\section{Hypotheses three}

It was hypothesized that there is a main effect of combat exposure on PTSD. The result represented as F $(3,249) 3092.335=130.206$, $\mathrm{P}<0.05$ was found to be significant.

\section{Hypotheses four}

It was hypothesized that there will be a significant main effect of religious affiliation on PTSD avoidance symptoms. Analysis revealed significance as $\mathrm{F}(1,249) 228.546=\mathrm{P}<0.05$.

\section{Hypothesis five}

It was hypothesized that there will be a significant main effect of religious affiliation on PTSD re-experiencing symptoms. Analysis revealed significance as $\mathrm{F}(1,249) 168.379=\mathrm{P}<0.05$.

\section{Hypothesis six}

It was hypothesized that there is a significant main effect of religious affiliation on hyperarousal symptoms. Analysis revealed that there was no significant main effect religious affiliation on hyperarousal symptoms. The result presented as $(1,249) 109.091=$ $\mathrm{P}>0.05$.

\section{Discussion}

From the presentation of results, religious affiliation and combat exposure were seen not to be significant on PTSD. This goes to a large extent to explain that religious affiliation and combat exposure have no impact on PTSD symptoms. The second hypothesis revealed a significant effect of religious affiliation on PTSD. This was significant and goes further to explain the positive relationship between religion and mental health outcomes, religion stands in as a buffer. ${ }^{11}$ Further to this is that being from the Christian or Muslim extraction has a relationship or impact on experiencing PTSD symptoms among military personnel. Thirdly, combat exposure was found to be significant on PTSD. As this military personnel is exposed to battlegrounds and combats, they are likely to develop PTSD. Dauda et al., ${ }^{37}$ Breslau, ${ }^{25}$ Hoge et al ${ }^{28}$ found a significant cause-effect relationship between combat exposure and PTSD. Brewin et al. ${ }^{40}$ also studied predictors of PTSD and showed that pre-trauma risk factors have relatively weak predictive effects, while trauma intensity and post-trauma risk factors have somewhat stronger predictive effects. For instance, a lack of social support, life stress, trauma severity, childhood abuse, and other adverse childhood experiences were strong predictors of PTSD. Fourthly, religious affiliation was found to be significant on avoidance symptoms. Because of the presence of cultural beliefs, and some level of religiosity, the combatants are likely to numb symptoms of distress even when the signs of distress are glaring. Being a Christian, Muslim or practicing other religion may contribute in numbing symptoms of PTSD may be due to high religiosity inherent in the different religious sects. Furthermore, religion was seen to be significant on re-experiencing symptoms. However, despite having PTSD, avoidance symptoms, and reexperiencing symptoms to be positive, the hyperarousal symptoms were found not to be significant with religious affiliation. ${ }^{41-50}$

\section{Conclusion}

The Nigerian military has been outstretched despite the meager amount of attention given to them. They will have to curb with the insurgency, territorial peace, act as parents, as guardians, and as the watchdogs of a society faced with anarchy. Continentally, they are faced with the task of global peace. In most of the places these military personnel are deployed to, they mostly lose touch with the social fabrics of their societies and as such religious activities are mostly self-driven and not a case where they mostly worship with brethren. This military personnel are often taken away for too long and upon return, they are likely not to be provided with the basic attention needed to help them recoup. At the war front, most of them do not communicate with family members, hence, the vacuum for social support is created. These individuals are likely to take in religious buffers to gain the necessary social support they require to have. It is thus recommended that:

1. Family support system should be buffered to be able to compliment with the available coping options to the military personnel

2. Religious institutions should incorporate counselling and mental health services within the framework of their activities. These services will help to address the roots of many challenges these personnel are facing.

3. There is a need for this military personnel to be provided with the basic psychosocial support they need at war fronts and even back home. There is always a need for psychological first aid, there will be a need for trauma debriefing at every interval they have covered

4. There is a need for their social support mechanisms to be improved. Some of these personnel need to be incorporated into positive and negative religious coping options which on the long-run they may find to be significant.

5. There should be recruitment of more and more staff into the system to reduce the workload on some few.

6. There is a need for this military personnel to be taught how to manage stress and stressors from their jobs.

7. More and more psychoeducation should be provided to these personnel on early signs and symptoms of PTSD and also educating them to know their limits and seek for help.

\section{Acknowledgment}

None.

\section{Conflict of interest}

None.

\section{References}

1. Rasic D, Robinson JA, Bolton J Bienvenu, et al. Longitudinal relationships of religious worship attendance and spirituality with major depression, anxiety disorders, and suicidal ideation and attempts: findings from the Baltimore epidemiologic catchment area study. Psychiatr Res. 2011;45(6):848-854.

2. Chang BH, Skinner KM, Boehmer U. Religion and mental health among women veterans with sexual assault experience, International Journal of Psychiatry in Medicine. 2001;31(1):77-95.

3. Chang BH, Skinner KM, Zhou C, et al. The relationship between sexual assault, religiosity, and mental health among male veterans. Int $J$ Psychiatry Med. 2003;33(3):223-239.

4. Bormann JE, Liu L, Thorp SR, et al. Spiritual wellbeing mediates PTSD change in veterans with military-related PTSD. Int J Behav Med. 2002;43(3):213-220.

5. Pargament KI, Sweeney PJ. Building spiritual fitness in the army: an innovative approach to a vital aspect of human development. Am Psychol. 2011;66(1):58-64. 
6. Niederhauser VP, Maddock J, LeDoux F, et al. Building strong and ready army families: a multirisk reduction health promotion pilot study. Mil Med. 2005;170(3):227-233.

7. Parker MW, Fuller GF, Koenig HG, et al. Soldier and family wellness across the life course: a developmental model of successful aging, spirituality, and health promotion, part II. Mil Med. 2001;166(7):561-570.

8. Harris JI, Erbes CR, Engdahl BE, et al. The effectiveness of a traumafocused spiritually integrated intervention for veterans exposed to trauma. J Clin Psychol. 2011;67(4):425-438.

9. Koenig HG, Cohen DG, Blazer C, et al. Religious coping and cognitive symptoms of depression in elderly medical patients. Psychosomatics. 1992;36(4):369-375.

10. Pargament KI, Isher K, Dubow E, et al. Methods of religious coping with the Gulf War: Cross-sectional and longitudinal analyses. Journal for the Scientific Study of Religion. 1994;33(4):347-361.

11. Koenig HG, Bussing A. The Duke University Religious Index (DUREL) A Five item measure use in epidemiological studies. Religions 2010 1(1):78-85

12. Koenig HG. Annotated bibliography of religion, spirituality, and medicine South Med J. 2006;99(10):1189-1196.

13. Fontana A, Rosenheck R. Trauma, change in the strength of religious faith, and mental health service use among veterans treated for VTSD. J Nerv Ment Dis. 2004;192(9):579-584

14. Chen YY, Koenig HG. Traumatic stress and religion: Is there a relationship? A review of empirical findings. Journal of Religion and Health. 2006;45(3):371-381.

15. Moreira-Almeida A, Neto EL, Koenig HG. Religiousness and menta health: a review. Revista Brasileira de Psiquiatria. 2006; 28(3):242-250.

16. Litz B, Stein N, Delaney E, et al. Moral injury and moral repair in war veterans: A preliminary model and intervention strategy. Clinical Psychology Review. 2009;29(8):695-706.

17. Maguen S, Metzler T, Litz B, et al. The impact of killing in war on mental health symptoms and related functioning. J Trauma Stress. 2009;22(5):435-443.

18. Wilson JP, Moran TA. Psychological trauma: Post-traumatic stress disorder and spirituality. Journal of Psychology and Theology. 1998;26(2):168-178.

19. Falsetti SA, Resick PA, Davis JL. Changes in religious beliefs following trauma. J Trauma Stress. 2003;16(4):391-398.

20. Drescher K, Foy D. Spirituality and trauma treatment: Suggestions for including spirituality as a coping resource. NCP Clinical Quarterly. 1995;5(1):4-5.

21. Friedman MJ, Resick PA, Bryant RA, et al. Considering PTSD for DSM5. Depress Anxiety. 2011;28(9):750-769.

22. Neria Y, Nandi A, Galea S. Post-traumatic stress disorder following disasters: a systematic review. Psychol Med. 2008;38(4):467-480.

23. Brewin CR. A systematic review of screening instruments for adults at risk of PTSD. J Trauma Stress. 2005;18(1):53-62.

24. Jones E, Wessely S. Shellshock to PTSD: Military Psychiatry from 1900 to the Gulf War. Hove and New York: Psychology Pres;2005.

25. Breslau N. Epidemiologic studies of trauma, posttraumatic stress disorder, and other psychiatric disorders. Can J Psychiatry. 47(10):923-929.

26. American Psychiatric Association. Diagnostic and statistical manual of mental disorders. $4^{\text {th }}$ ed, Washington, DC;2000.

27. Dohrenwend BP, Turner JB, Turse NA, et al. Continuing controversy over the psychological risks of Vietnam for U.S. veterans. J Trauma Stress. 2007;20(4):449-465

28. Hoge CW, Castro CA, Messer SC, et al. Combat duty in Iraq and Afghanistan, mental health problems, and barriers to care. The NEngl J Med. 2004;351(1):13-22.

29. Booth-Kewley S, Larson GE, Highfill-McRoy RM, et al. (2010) Correlates of posttraumatic stress disorder symptoms in Marines back from war. $J$ Trauma Stress. 2010;23(1):69-77.

30. Hoge CW, Terhakopian A, Castro CA, et al. Association of posttraumatic stress disorder with somatic symptoms, health care visits, and absenteeism among Iraq war veterans. Am J Psychiatry. 2007;164(1): 150-153.

31. Trickey D, Siddaway AP, Meiser-Stedman R, et al. A meta-analysis of risk factors for post-traumatic stress disorder in children and adolescents. Clin Psychol Rev. 2012;32(2):122-138.

32. Hoge CW, Lesikar SE, Guevara R, et al. Mental disorders among U.S. military personnel in the 1990s: association with high levels of health care utilization and early military attrition. The American Journal of Psychiatry. 2002;159(9):1576-1583

33. Meis LA, Eibers CR, Polusny MA, et al. Intimate relationships among returning soldiers: The moderating roles of negative emotionality, PTSD symptoms and alcohol problems. J Trauma Stress. 2010;23(5):564-572.

34. Sherman MD, Zanotti DK, Jones DE. Key elements in couples therapy with veterans with combat-related posttraumatic stress disorder. Professional Psychology: Research and Practice. 2005;36(6),626-633.

35. Cardozo BL, Kaiser R, Gotway CA. Mental health, social functioning, and feelings of hatred and revenge of Kosovar Albanians one year after the war in Kosovo. J Trauma Stress. 2003;16(4):351-360.

36. De Jong J, Komproe I, van Ommeren M, et al. Lifetime events and posttraumatic stress disorder in four post-conflict settings. JAMA. 2001;286(5):555-562.

37. Dauda AS, Abel J, Caleb MS. The wound of religious violence and terrorism in Nigeria: Post Traumatic Stress Disorder. International Journal of Humanities and Social Sciences. 2016;4(1):209-214.

38. Keane TM, Fairbank JA, Caddell JM, et al. Clinical evaluation of a measure to assess combat exposure. Psychological Assessment. 1989;1(1):53-55.

39. Weathers F, Litz B, Herman D, et al. The PTSD Checklist (PCL): Reliability, Validity, and Diagnostic Utility. Paper presented at the Annual Convention of the International Society for Traumatic Stress Studies. 1993.

40. Brewin CR, Andrews B, Valentine JD. Meta-analysis of risk factors for posttraumatic stress disorder in trauma-exposed adults. $J$ Consult Clin Psychol. 2000;68(5):748-766.

41. Begic D, Jokic-Begic N. Aggressive behavior in combat veterans with post-traumatic stress disorder. Mil Med. 2001;166(8):671-676.

42. Friedman MJ. PTSD History and Overview. National Center for PTSD 2007.

43. Glas G. Anxiety, anxiety disorders, religion and spirituality, Southern Medical Journal. 2007;100(6):621-625.

44. Koenig HG, Cohen DG, Blazer C, et al. Religious coping and cognitive symptoms of depression in elderly medical patients. Psychosomatics. 1995;36(4):369-375.

45. Koenig HG, Cohen HJ. Spirituality across the lifespan. Southern Medical Journal. 2000;99(10):1157-1158.

46. Norris FH, Friedman MJ, Watson PJ, et al. 60,000 disaster victims speak Part I. An empirical review of the empirical literature, 1981-2001. Psychiatry. 65(3):207-239. 
47. Pargament KI. Of means and ends: Religion and the search for significance. International Journal for the Psychology of Religion. 1992;2(4):201-229.

48. Pargament KI. Religious methods of coping: Resources for the conservation and transformation of significance. In: E. Shafranske, editor. Religion and the Clinical The practice of Psychology, American Psychological Association: Washington, DC; 1996;215-239.
49. Pargament kI. The psychology of religion and coping: Theory, research, practice. New York: Guilford;1997.

50. Pargament KI, Smith BW, Koenig HG, et al. Patterns of positive and negative religious coping with major life stressors. Journal for the Scientific Study of Religion. 1998;37(4):710-724. 